Romanes, G. J. (Scotland) thought the answer to that was Yes. The grey matter was much more vascular in capillary veins than the white matter.

Wolman, L. (England) said he was particularly interested in the difference between anterior and posterior horns, where they had the concentration of nerve cells. Did the capillary network correlate with the increased number of nerve cells? Was there any difference?

RomanEs, G. J. (Scotland) replied that if one took the actual density of nerve cells the density would be in the anterior horn, in areas where there were big motor cells taking up a great deal of room. In the posterior horn the density of nerve cells was quite high. If one counted these they were higher in the posterior horn in the intermediate region than they were in the lateral part of the anterior horn in the lumbar enlargement. What was interesting was the fact that the tip of the posterior horn was supplied from the posterior spinal vessels, while one had the remainder of the grey matter supplied from the perforating branches of the anterior spinal artery but, where they joined, there was no evidence of junction; there must be anastomosis of capillary fields, because there was no break that one could see, and yet on injecting one vessel one filled one territory and on injecting the other one filled another territory. horn?

Wolman, L. (England). It looked the same in both anterior and posterior

Romanes, G. J. (Scotland). Agreed. He had not done actual measurements of density. Horn Cragie had done quite a lot of this at one time, measuring the lengths of capillaries in a given volume of grey and white matter, but as far as he could recall the figures did not seem to show any difference.

\title{
THE PATHOLOGY OF VASCULAR DISORDERS OF THE SPINAL CORD
}

\author{
By J. Trevor Hughes, M.D. \\ The Radcliffe Infirmary, Oxford
}

THE spinal cord has one of the most complex blood supplies of any part of the body and it is necessary to understand some of its complexity before turning to the problem of its vascular disorders. At this meeting we have been fortunate in hearing Professor Romanes' excellent account of the anatomy of the spinal cord vascular supply. Reflecting on the complicated pattern of blood supply I should like to pick out the features that have a special importance in the pathology of vascular disorders of the spinal cord:

I. The multiplicity of feeding sources into the spinal arterial system. This forms a powerful reserve of arterial supply immune except to interruption at specially vulnerable places.

2. The dependence on a moderate number of tributary arteries of inconstant position and which are relatively so large that the other tributaries may be interrupted with impunity.

3. The strict division into anterior and posterior spinal artery territories which supply two-thirds and one-third of the cross-sectional area respectively.

4. The absence of significant anastomosis between anterior and posterior spinal artery circumferentially around the cord. (But the anterior spinal 
artery does make a good anastomosis with the posterior spinal arteries around the Cauda equina.)

5. The overwhelming importance in the whole system of the single anterior spinal artery.

6. The reserve of venous drainage so that venous obstruction rarely damages the spinal cord.

The possible sites of obstruction to the vascular supply of the spinal cord may be grouped under seven headings. In group I we have the aorta to which the subclavian artery is added. The internal iliacs could be included but in this context are of no importance. Group 2 consists of the vertebral arteries whose peculiar anatomical situation merits separate consideration. In group 3 are the paired aortic branches such as the intercostals and the lumbar arteries and in group 4 are the radicular tributaries to the anterior and posterior spinal arteries, these tributaries accompanying the nerve roots through the intervertebral foramina. Group 5 comprises the anterior and posterior spinal arteries, and group 6 all the small spinal arteries arising from the anterior and posterior spinal arteries. In group 7 are the veins of the spinal cord.

\section{TABLE}

Vascular Disorders of the Spinal Cord

(Analysis of 28 necropsies selected from a 20-year period)

\begin{tabular}{|c|c|c|c|}
\hline Site of Lesion & \multicolumn{2}{|l|}{ Cause } & $\begin{array}{l}\text { Number } \\
\text { of Cases }\end{array}$ \\
\hline \multirow{3}{*}{$\begin{array}{l}\text { I. Aorta } \\
\text { (5 cases) }\end{array}$} & Atheroma & . & 3 \\
\hline & Dissecting aneurysm & . & I \\
\hline & Trauma & ${ }^{\circ}$ & I \\
\hline \multirow{5}{*}{$\begin{array}{l}\text { 2. Vertebrals } \\
\text { ( } 2 \text { cases) } \\
\text { 3. Intercostals } \\
\text { (I case) } \\
\text { 4. Radicular tributaries } \\
\text { (IO cases) }\end{array}$} & Trauma & . & 2 \\
\hline & Thoraco-lumbar sympat & tomy & I \\
\hline & Malignant infiltration . & & 8 \\
\hline & Tuberculosis (Psoas absc & & I \\
\hline & Herpes Zoster & & I \\
\hline \multirow{3}{*}{$\begin{array}{l}\text { 5. Anterior spinal artery } \\
\text { (4 cases })\end{array}$} & Thrombosis (Idiopathic) & & I \\
\hline & Thrombosis (Cervical $\mathrm{S}$ & dylosis) & I \\
\hline & Ischaemia (Cervical Spo & losis) & 2 \\
\hline \multirow{4}{*}{$\begin{array}{l}\text { 6. Small spinal arteries } \\
\text { ( } 4 \text { cases }) \\
\text { 7. Veins } \\
(2 \text { cases })\end{array}$} & Tuberculosis meningitis & . & 3 \\
\hline & Syphilis (Erb’s) & & I \\
\hline & Foix-Alajouanine disease & . & 2 \\
\hline & Total . & . & 28 \\
\hline
\end{tabular}

The series of cases that I now wish to present to you has been gathered from the material of our neuropathology department at Oxford and comprises 28 necropsied cases drawn from a twenty-year period. The table shows these 28 cases divided into the groups that I have enumerated. I propose to deal with each group in turn but have selected one case from each group for detailed description. 
Group I. Aortic Cases. Aortic atheroma is very common, but it is rare for the clinical worker to attribute spinal cord ischaemia to this cause. In three cases severe aortic atheroma had caused ischaemic areas in the spinal cord, the clinical course being an ill-defined chronic paraparesis. The commonest aortic cause of acute spinal cord ischaemia is probably dissecting aneurysm, in which the dissection of the tunica media by a haematoma compresses the origins of the intercostal or lumbar arteries. In these cases the clinical signs of neurological involvement are often slight and scrutiny of the spinal cord shows only trivial findings. But when an important intercostal or lumbar artery is blocked extensive spinal cord infarction can occur.

The case I now wish to describe was most unusual in being caused by aortic trauma. It has been described in more detail elsewhere (Hughes, I964a).

Case Report. A 62-year-old housewife crashed her car into a shop, suffering injuries to her chest and a lacerated chin. Although momentarily unconscious she was able to walk away from her car and an ambulance took her to hospital. On admission she was found to have fractures of the $2 \mathrm{nd}$, $3 \mathrm{rd}$ and 4 th ribs anteriorly with a progressive left haemothorax necessitating a thoracotomy the following day. Removal of two litres of blood from the left hemithorax disclosed a $2.5-\mathrm{cm}$. tear in the pleura over the aorta just above the diaphragm, and extensive mediastinal bruising. With massive blood transfusion her general condition was restored but on the $4^{\text {th }}$ post-operative day impaired movement of the legs was noticed and a full neurological examination the following morning showed complete paralysis of the legs and absence of all sensation up to the level of $\mathrm{T}_{3}$. Plain X-rays of the spine showed no fracture and a myelogram did not demonstrate any evidence of spinal block. On the 6th post-operative day the patient's blood pressure suddenly collapsed and 15 minutes later she died. At necropsy the thoracic aorta showed a transverse intimal tear almost encircling the aorta at a level $4 \mathrm{~cm}$. below the origin of the left subclavian artery. The tear was plugged with thrombus continous with a large mural haematoma in the damaged tunica media and adventitia. At their origin the 2 nd, $3 \mathrm{rd}, 4^{\text {th }}$ and 5 th intercostal arteries were surrounded and compressed by the mural haematoma. The spinal cord showed extensive infarction from $\mathrm{T}_{3}$ to $\mathrm{T}_{7}$ (not examined caudal to $\mathrm{T}_{7}$ ) the whole diameter of the cord being involved. Neurones were absent and the myelin and axons broken up with a perivascular polymorph reaction but few lipid phagocytes. A round infarcted area was present in the posterior columns of $\mathrm{C}_{7}$ and minor ischaemic changes in $\mathrm{C}_{7}, \mathrm{C} 8, \mathrm{~T} \mathrm{I}$ and $\mathrm{T} 2$.

Group 2. Vertebral Artery Cases. My experience with obstruction of the vertebral artery (Hughes, I964b) is confined to two almost identical cases one of which I shall describe.

Case Report. A 52-year-old factory worker was knocked down by a car, being momentarily unconscious and having scalp lacerations, fractures of the left humerus and right clavicle and intra-abdominal bleeding from a ruptured spleen. With splenectomy and massive transfusion his general condition improved but the following day it was clear he had a partial cord transection causing a quadriparesis. Initially affecting the lower cervical cord segments it then spread upwards causing respiratory difficulty resulting in his death on the third day after his accident. The most interesting necropsy findings were in the cervical spine. The prevertebral muscles were infiltrated with haematoma which covered a tear through the $\mathrm{C}_{5}-6$ intervertebral disc. The spine was mobile due to this and to loosening of the capsular ligament around the intervertebral joints. No fractures could be seen and the spinal canal was not otherwise abnormal. When the vertebral arteries were exposed they were seen to be kinked as they passed through the region of the disc tear. The left vertebral artery was partially torn and embedded in blood clot. The 
spinal cord externally showed slight swelling and a bloodless anterior spinal artery from $\mathrm{C}_{4}$ to $\mathrm{C}_{7}$. The sections showed ischaemic changes from $\mathrm{C}_{1}$ to $\mathrm{C}_{3}$ then frank infarction from $\mathrm{C}_{4}$ to $\mathrm{C} 6$.

Group 3. Intercostal Arteries. This group consists of the cases where the paired aortic branches such as the intercostal and lumbar arteries are involved. Such cases have most frequently resulted from surgery. Thoracoplasty and pneumonectomy have often been responsible, but the following case resulted from a thoraco-lumbar sympathectomy. It has been described in greater detail elsewhere (Hughes \& MacIntyre, I963).

Case Report. A 44-year-old female bank clerk developed malignant hypertension which was first diagnosed in 1947. By 1950 her blood pressure ranged from I40/130 to 260/I 50 and she entered St. Mary's Hospital, Paddington, for a thoraco-lumbar sympathectomy. The left sympathetic chain, from T2 to L2 plus the splanchnic nerves, was extirpated at the first operation which was performed without incident. Three months later she was readmitted for a similar operation on the right side. The right sympathetic chain, from TI to L2 plus the splanchnic nerves, was removed through the bed of the ninth rib with opening of the pleural cavity. No difficulty was encountered and the fall in blood pressure during the operation was not thought to be excessive. On recovery from the general anaesthesia, paraparesis and sensory loss below $\mathrm{T}_{9}$ level were immediately apparent. The lumbar spinal fluid was normal. The paresis and anaesthesia partially recovered but on discharge four months later she was only able to walk a few yards with a stick and a caliper on the right leg. Both legs remained spastic and without perception of pain, temperature and vibration but with some sensibility of touch and joint movement. Her neurological state remained unchanged during the subsequent to years during which period the level of the blood pressure ascended. Two weeks before her last admission she became suddenly dizzy and lost consciousness due to subarachnoid haemorrhage from a ruptured aneurysm on the left anterior cerebral artery. She died from a further bleed six days after admission.

At necropsy there were pathological changes of hypertension and extensive subarachnoid bleeding from a ruptured left anterior cerebral aneurysm. The spinal cord from T6 to LI was shrunken, the anterior half of the cord being affected. Examination of the radicular arteries showed large vessels accompanying left $\mathrm{C}_{3}$, right $\mathrm{C} 8$, left $\mathrm{T}_{\mathrm{I}}$, then a big gap until left L2 root. Hence there was no major tributary to the anterior spinal artery between TI and L2 segments. The missing vessel in all probability was the right T 9 tributary this being disturbed during the second operation of right thoraco-lumbar sympathectomy.

Group 4. Radicular Tributary Cases. The group of cases where arterial obstruction had occurred in the intervertebral foramina included several of advanced malignant disease of the spine. In these the spinal canal was normal but the cord was infarcted by a mass of malignant tumour infiltrating the intervertebral foramina. The case of psoas abscess operated in a similar manner but in the case of herpes zoster that I wish to present the spinal cord infarction was caused in a most unusual manner. It is not generally realised that the lesion of herpes zoster is an infarct of the posterior root ganglion, and that there is in this disease a tendency to thrombosis. When the posterior root ganglion affected has an accompanying important radicular tributary extensive spinal cord infarction may occur as happened in this case.

Case Report. A woman of 8I years developed typical herpes zoster vesicles over her right shoulder posteriorly, then a few days later developed weakness of both arms and legs with extensor plantar responses. Sensory impairment was also present over most 
of the body below a level in the upper cervical dermatomes. Breathing was hampered by intercostal paresis and within four days of her admission she died.

At necropsy there was a recent cardiac infarct with mural thrombus and emboli in the pulmonary and renal arteries. The brain showed a recent infarction of the caudal part of the anterior cerebral artery. The spinal cord showed ischaemic changes just short of frank infarction extending from $\mathrm{C}_{7}$ to $\mathrm{T}_{\mathrm{I}}$. The major spinal cord vessels were patent. This localised infarction corresponded to obstruction of a radicular artery accompanying some nerve root between $\mathrm{C}_{7}$ and $\mathrm{T}_{1}$ and would correspond to an infarction caused by the herpes zoster infection.

Group 5. Anterior Spinal Artery Cases. I have seen four cases of anterior spinal artery disease all of slightly different etiology. One was a thrombosis of the caudal part of the artery causing the typical infarction of the anterior part of the spinal cord. The remaining cases were due to cervical spondylosis, in two a chronic ischaemic process, but one an acute anterior spinal artery thrombosis. This latter case was most unusual and the details are interesting and have been published elsewhere (Hughes \& Brownell, I964).

Case Report. A woman of 70 years whilst dressing suddenly developed pain across the back of her shoulders followed by tingling and numbness of both hands, which she noticed to be weak. On examination the cranial nerves were normal. Flexion of the neck was resisted because of pain. Both arms showed flaccid paralysis complete in the upper arm but incomplete in the lower arm and hands. The power in the legs was normal, the tendon reflexes were present and the plantar responses flexor. The only loss in sensation was a diminution in perception of pinprick on the ulnar border of both hands. During the day of admission the legs became weak and she was unable to stand. All limbs became flaccid and no reflexes were obtainable. Her chest muscles were paralysed and she finally died the day after admission.

At necropsy the lungs were markedly collapsed. The spine showed in its thoracic region moderate kyphos and scoliosis, but this had not damaged the spinal cord. In the cervical region there were spondylotic bulges in association with $\mathrm{C}_{3}-4, \mathrm{C}_{4}-5$ and $\mathrm{C}_{5}-6$ discs, the first two discs having low tranverse ridges and $\mathrm{C}_{5}-6$ having two symmetrical lateral eminences. None of these bulges was more than $\mathrm{I} \mathrm{mm}$. high but there was added antero-posterior narrowing of the canal by osteophytosis. The vertebral arteries were examined and found free from atheroma and widely patent throughout. The spinal cord showed indentations at $\mathrm{C}_{4}-5, \mathrm{C}_{5}-6$ and $\mathrm{C} 6-7$ segments, these corresponding to the spondylotic bulges. Histological examination of the spinal cord showed from $\mathrm{C}_{4}$ to $\mathrm{T}_{\mathrm{I}}$ a large continuous zone of infarction symmetrically placed in the distribution of the anterior spinal artery. The whole of the anterior white column together with adjacent areas of the lateral and posterior white columns was affected. Of the grey matter the infarction involved the anterior horns and most of the grey commissure. In all the segmental levels from $\mathrm{C}_{5}$ down to $\mathrm{C} 8$ ante-mortem thrombus was present in the anterior spinal artery, in an occasional sulcal artery (C5) and in an occasional small vessel in the grey commissure $\left(\mathrm{C}_{5}-6\right)$. The changes in the infarcted region were everywhere recent and comparable to the age of the arterial thrombus which was well developed, attached to the vessel wall but not organised.

Group 6. Small Spinal Arteries. In the next group of cases the small spinal arteries are involved. My experience includes one case of spinal syphilis and three of tuberculous meningitis. In these cases endarteritis obliterans of the small spinal arteries causes extensive vascular damage to the spinal cord. The following case will demonstrate just how bad the damage may be.

Case Report. A 20-year-old Austrian au-pair girl one week after her arrival in 
England developed an illness which proved to be tuberculous meningitis. She also had evidence of generalised tuberculosis since her chest X-ray showed miliary tuberculosis and she had evidence of tuberculous endometritis. Her initial treatment was at the Atkinson Morley Hospital, but after one month she was transferred to the tuberculous meningitis unit at Oxford. By now she had a complete paraplegia which made little improvement up to her death five months after the onset of her illness.

At necropsy the brain was swollen with thick exudate at the base and miliary tubercles elsewhere in the leptomeninges. On slicing the brain, the lateral, third and fourth ventricles were dilated due to obstruction at the base of the brain. The spinal cord showed a remarkable appearance. The dura mater was distended from top to bottom by thick yellow exudate surrounding the cord. It was not possible to open and reflect the dura in the usual way so it was examined in transverse sections. These showed at all the levels examined that the spinal cord was surrounded by thick tuberculous granulation tissue in the subarachnoid space. The small spinal arteries were buried in the exudate and often showed endarteritis obliterans. The spinal cord showed severe ischaemic changes often amounting to infarction.

Group 7. Venous Cases. The last group concerns the veins of the spinal cord. Involvement of these is rare, but there does exist a form of spinal cord angioma whose etiology is disputed but is characterised by enormous venous distension. The condition is also called Foix-Alajouanine disease or subacute necrotic myelitis. The following case is typical.

Case Report. A man of 64 presented in 1960 with low back pain of increasing severity over the preceding year, associated with the gradual onset of weakness in both lower limbs, difficulty with micturition, and constipation. On admission to the Radcliffe Infirmary his state was a spastic paraparesis with loss of sensation to pin-prick and cottonwool over the $\mathrm{L}_{4}$ to $\mathrm{S}_{2}$ segmental areas. A lumbar myelogram showed partial obstruction and distortion of the myodil column at TII-TI2. At operation a widespread angiomatous malformation of the spinal cord was seen over segments TI I and TI2. No surgical treatment could be offered; he was discharged unchanged and eventually admitted to Cowley Road Hospital, where he died a year after his admission and two years after the onset of his symptoms.

At necropsy, there were pressure sores, and bronchopneumonia. The cardiovascular system appeared normal and in particular the inferior vena cava and its tributaries were patent and free from thrombus. The brain was normal. The spinal canal and meninges were normal apart from the laminectomy operation scar. The findings in the vessels could be divided into those in the arteries, veins, the additional abnormal vessels and the capillaries.

Arteries. The anterior spinal artery was patent throughout, of normal calibre and received large tributaries accompanying left $\mathrm{C}_{5}, \mathrm{~T}_{3}$ and right $\mathrm{LI}_{\text {. }}$. Its only abnormality was that in the sacral region there were several arteries in the position of the anterior spinal artery.

Veins. These were numerous, dilated and with thickened walls but situated normally on the posterior aspect of the cord and adjacent to the anterior spinal artery. In some there was evidence of former thrombosis.

Abnormal Vessels. In addition to the normal spinal cord vessels there was a large coiled mass of dilated abnormal vessels, blue due to their distension with blood. These extended from Ti I to $\mathrm{L}_{4}$ and appeared external and additional to the normal venous system.

Capillaries. Proliferation of capillaries had occurred throughout the segments of the spinal cord affected by necrosis. The necrosis was most severe at TI I, LI was moderately affected and slight changes were present at $S_{I}$.

The pathogenesis of this condition is disputed. In this case the angiomatous mal- 
formation was probably an abnormal arteriovenous communication and the spinal cord necrosis due to bypassing of the normal capillary bed with venous thrombosis as an added factor.

I have now come to the end of this survey of my experience of vascular disorders of the spinal cord. Charcot in 1870 wrote 'vascular disorders whether due to embolism or thrombosis are unknown in the spinal cord'. Perhaps I have convinced you by these cases that in the occasional case a myelopathy has a vascular basis.

Finally I wish to thank the many clinicians and pathologists principally of the Oxford region but also sometimes further afield who were responsible for that vital portion of anatomy, the spinal cord, coming to me for examination.

\title{
REFERENCES
}

Hughes, J. T. (1964a). Brit. med. F. In press.

Hughes, J. T. (1964b). Int. F. Paraplegia, 2, I.

Hughes, J. T. \& BRownel L, B. (1964). Neurology (Minneap.). In press.

Hughes, J. T. \& McIntyre, A. G. (I963). F. Neurol. Neurosurg. Psychiat, 26, 4I8.

\section{THE DISTURBANCE OF CIRCULATION IN TRAUMATIC PARAPLEGIA IN ACUTE AND LATE STAGES: A PATHOLOGICAL STUDY}

\author{
By Lionel Wolman, M.A., M.D., Ph.D., M.R.C.P., D.P.M. \\ Department of Neuropathology, Royal Infirmary, Sheffield 6
}

THE material on which this investigation of the circulatory disturbances occurring in traumatic paraplegia is based consists of the autopsy findings in 95 cases examined in the period I952 to I963. Most of these cases had been admitted to the Spinal Injuries Centre at Lodge Moor Hospital, Sheffield, under the care of Dr. A. G. Hardy. Being a post-mortem pathological study, no physiological observations on the circulation during life are included. As full autopsies were carried out in these cases it has been possible to divide the pathological findings into those vascular disturbances encountered in the general examination and those found on detailed investigation of the damaged spinal cord.

TABLE I

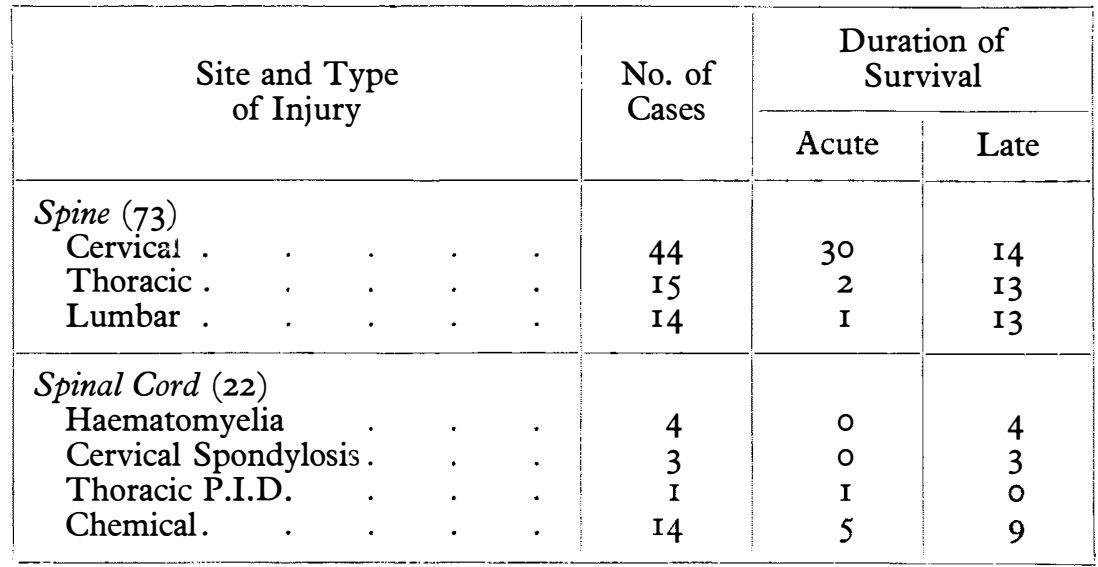

